\title{
Сравнение силы взаимосвязи показателей экономической прибыли и рыночной стоимости акций
}

\author{
Блинов С.С. ${ }^{4}$, Найденова Ю.Н. ${ }^{5}$
}

В работе представлен теоретический обзор двух моделей: экономической добавленной стоимости и модели Эдвардса-Белла-Ольсона. Ключевое различие между ними заключается в том, что ЕVА рассчитывается на основе инвестированного капитала, тогда как экономическая прибыль, определяемая по модели ЕВО, - на основе собственного капитала. В связи с этим была выдвинута гипотеза о том, что экономическая прибыль, определяемая по модели ЕВО, лучше объясняет капитализащию компании и рыночную добавленную стоимость, чем ЕVА. Полученные выводы свидетельствуют о том, что оба показателя имеют более слабую взаимосвязь с рыночной капитализацией компании, чем традиционные показатели отчетности (а именно чистая прибыль, ЕАТ). Однако при этом показатель экономической прибыли, рассчитанный по модели ЕВО, значительно превосходит EVA и ЕАТ в способности объяснять рыночную добавленную стоимость.

$$
\text { JEL: } G 30
$$

Ключевые слова: модели добавленной стоимости, экономическая прибыль, модель ЕVA, модель ЕВО, стоимость собственного капитала

Активное развитие концепции управления компанией на основе стоимости (Value-based management) сделало стоимость фирмы ключевым результирующим показателем еe деятельности, на основе которого оценивается эффективность работы менеджмента и деятельность компании в целом. В качестве индикатора создания или разрушения стоимости был разработан ряд моделей экономической прибыли, таких как экономическая добавленная стоимость (Economic Value Added, EVA) и еe модификации, модель Эдвардса-БеллаОльсона (Edwards-Bell-Ohlson model, EBO), акционерная добавленная стоимость (Shareholder Value Added, SVA), денежная добавленная стоимость (Cash Value Added, CVA) и др.

Для оценки эффективности работы компании и ее менеджмента инвесторам необходим показатель, который бы отражал инвестиционную привлекательность компании. При этом рыночная стоимость собственного капитала слишком волатильна и подвержена временному влиянию неподтвержденной информации и нерационального поведения инвесторов. Кроме того, собственный капитал многих компаний не котируется на фондовом рынке и поэтому не подвергается постоянной актуальной оценке. Таким образом, существует потребность в показателе стоимости, который может быть определен для компании любой организационноправовой формы, в каждый момент времени на основе доступной информации о деятельности компании.

\section{Анализ и критика модели экономической добавленной стоимости}

На текущий момент одной из наиболее освещенных в теоретической литературе и эмпирических исследованиях является модель экономической добавленной стоимости Economic Value Added или EVA, методика расчета которой была предложена Стерном и Стюартом (Stern, 2001), а затем внедрена во многих компаниях по всему миру

\footnotetext{
4 Преподаватель кафедры финансового менеджмента, младший научный сотрудник Лаборатории инвестиционного анализа НИУ-ВШЭ - Пермь.

5 Преподаватель кафедры финансового менеджмента, младший научный сотрудник Лаборатории инвестиционного анализа НИУ-ВШЭ - Пермь.
} 
консалтинговой компанией Stern Stewart \& Co. Теоретической основой модели авторы называют работы Миллера и Модильяни за 1958-1961 годы, в которых утверждалось, что экономическая прибыль является источником создания ценности фирмы, а барьерная доходность (или стоимость использования капитала) определяется риском инвесторов (Stern, 2001). Концепция экономической прибыли была сформулирована ранее Маршаллом как «то, что остается от бухгалтерской прибыли после вычета процентов за использование капитала по текущей ставке, может быть названо прибылью, заработной компанией или менеджментом» (Marshall, 1890). Основным вкладом Стерна, Стюарта, а также их последователей является четкая последовательная методология корректировки отчетности, которая позволяет сравнивать эффективность компаний, различающихся по методам финансирования, по степени использования интеллектуального капитала, по величине создаваемых резервов и другим особенностям деятельности.

Согласно утверждениям сторонников данной модели, EVA отражает эффективность работы компании с точки зрения ее акционеров. Дальнейшее развитие концепции VBM несколько сдвинуло это восприятие - прирост стоимости компании стал ключевым показателем деятельности для всех заинтересованных сторон или стейкхолдеров компании работников, кредиторов, государства, общества (Pohlman, 2000; Stern, 2001). В таком случае возникает вопрос, отражает ли добавленная стоимость ценность, созданную компанией для ее акционеров?

Значительная часть теоретической критики EVA заключается в том, что для расчета используется бухгалтерское значение величины капитала компании, которое значительно расходится с его рыночной оценкой. Фернандес сравнивает расчет EVA с показателем создания стоимости для акционеров SVC (Shareholder value creation), определяемым посредством умножения рыночной стоимости собственного капитала на разность между доходностью на собственный капитал и затратами на него. В результате он приходит к выводу, что показатели, основанные на бухгалтерских величинах, такие как экономическая добавленная стоимость EVA и экономическая прибыль ЕР, в принципе не способны отражать создание стоимости для акционеров (Fernandez, 2001).

Другой аспект активной критики EVA сосредоточен на результатах эмпирических исследований. Компания Stern Stewart \& Со создает и распространяет базы данных о величине экономической добавленной стоимости компаний США, Великобритании, Японии и других стран, а также расчет показателя основан на общедоступной информации для компаний, акции которых торгуются на фондовом рынке. Благодаря этому активно проводятся исследования взаимосвязи стоимости компании и EVA в различных страновом, отраслевом и других разрезах, а также с учетом дополнительных факторов. Начиная с момента разработки показателя и его внедрения в практику управления, ежегодно публикуются исследования по данной тематике, однако результаты их противоречивы. Приведем некоторые из них.

Одними из первых работ в данной области являются исследования О‘Бирна, показывающие взаимосвязь рыночной капитализации и доходности акций компаний и их EVA (O’Byrne, 1996). Несмотря на положительные выводы автора, даже с учетом дополнительных модификаций величина EVA смогла объяснить лишь чуть больше половины изменения стоимости компаний (56\%), немногим больше, чем операционная прибыль, отраженная в бухгалтерской отчетности. Такие же результаты получили Биддл, Боуэн и Воллес (Biddle, Bowen, Wallace, 1999), Тсуджи (Tsuji, 2006) и Ким (Kim, 2006). С другой стороны, близкое по спецификации модели исследование Ивашковской и Слободиной, проведенное на выборке телекоммуникационных компаний стран БРИК, привело к выводу о высокой взаимосвязи EVA и стоимости собственного капитала компании (Ивашковская, Слободина, 2009).

Исследования взаимосвязи доходности акций и экономической добавленной стоимости также не показали способности EVA эффективно отражать рост благосостояния акционеров за счет прироста стоимости акций (Chenn, Dodd, 1998; Biddle, Bowen, Wallace, 1999; West, 
Worthington, 2004; Maditinos, Šević, Theriou, 2005). Во всех перечисленных работах авторы пришли к выводу о том, что экономическая добавленная стоимость не превосходит такие показатели бухгалтерской отчетности, как операционная прибыль после уплаты налогов (NOPAT), чистая прибыль и показатели рентабельности, в качестве объяснения различий в доходности акций. Аналогичные результаты получили в работах, где модель доходности акций модифицирована - скорректирована на рыночную доходность - и отражает эффективность работы компании как способность обеспечить акционерам доходность свыше среднерыночной (West, Worthington, 2004; Ismail, 2006; Visaltanachoti, Robin, Yi, 2008).

Другая модификация показателя доходности - показатель полной доходности, полученной держателями обыкновенных акций компании за период (TSR, Total Shareholder Return). Помимо прироста цены акции TSR также учитывает величину выплаченных дивидендов и корректировки, отражающие влияние изменений собственного капитала, таких как выкуп акций, обмен акций дополнительной эмиссии в акции присоединяемых компаний, дополнительная эмиссия акций для продажи через IPO или SPO или другими способами (Романов, Кукина, 2008). Исследование Романова и Кукиной выявило, что темпы роста EVA не могут объяснить TSR в большей степени, чем изменение доходности рыночного индекса.

Простой корреляционный анализ связи EVA и прироста добавленной рыночной стоимости MVA, рассчитанной по рыночным данным о стоимости собственного капитала компании, показывает их низкую линейную взаимосвязь (Fernandez, 2001), что говорит о том, что EVA не отражает увеличения благосостояния собственников компании.

Таким образом, независимо от предполагаемой модели взаимосвязи экономической добавленной стоимости и благосостояния акционеров, лишь одно из рассмотренных исследований показало их тесную взаимосвязь. Возможно, причиной этого является то, что EVA рассчитывается на основе данных о фирме в целом - с учетом денежного потока на всех инвесторов и барьерной ставки доходности фирмы, а не сфокусирована на анализе собственного капитала.

Таким образом, можно предположить, что для анализа эффективности использования капитала акционеров компании необходим показатель экономической прибыли, основанный на информации о величине собственного капитала и требованиях владельцев к его доходности. Одной из таких моделей является модель Эдвардса-Белла-Ольсона (EBO).

\section{Анализ и критика модели Эдвардса-Белла-Ольсона}

Модель ЕВО строится на предположении, что инструментарий бухгалтерского учета следует принципу «чистого прироста», который говорит о том, что только доходы и дивиденды будут изменять балансовую стоимость капитала. В свою очередь балансовая стоимость собственного капитала предстает в модели как функция от балансовой стоимости и анормальных доходов. При разработке модели Ольсон, один из ее авторов, ставил перед собой цель проанализировать взаимосвязи между рыночной стоимостью фирмы с текущими/ожидаемыми доходами, балансовой стоимостью капитала и дивидендами. Для этого он использовал неоклассический подход к оценке ценных бумаг, который предполагал, что рыночная стоимость акции равна сумме дисконтированных дивидендов. Введя предпосылку о «чистом приросте», Ольсон заменил дивиденды на доходы и балансовую стоимость капитала, отмечая, что подобные выплаты акционерам снижают балансовую стоимость, при этом не влияя на текущие доходы. Он пришел к выводу, что «рыночная стоимость равняется балансовой стоимости, скорректированной на текущую рентабельность, измеренную с помощью анормальных доходов и прочих информационных массивов, которые улучшают качество прогнозов относительно будущей рентабельности» (Ohlson, 1995).

Фелтам и Ольсон (Feltham and Ohlson, 1995) проверили, каким образом единовременное представление бухгалтерских данных, отражающих результаты операционной и финансовой деятельности, влияет на рыночную стоимость. Кроме того, в 
данном исследовании они доказали эквивалентность модели ЕВО, модели дисконтирования дивидендов и модели дисконтирования денежных потоков. Наряду с этим они показали, каким образом элементы традиционной системы бухгалтерского учета влияют на взаимосвязь между рыночной стоимостью и рентабельностью. Их вывод заключался в следующем: начисленные доходы в большей степени объясняют изменения в рыночной стоимости, чем денежные потоки.

Наряду с этим Бернард (Bernard, 1995) исследовал влияние бухгалтерского представления информации на рыночную стоимость через показатель ЕВО. В своем исследовании он использовал прогнозы агентства Value Line относительно доходов, балансовой стоимости и дивидендов ряда американских компаний. Бернард сравнивал качество прогнозов стоимости фирмы, построенных на бухгалтерских цифрах и на дивидендах. Полученные эмпирические результаты показали, что объясняющая способность прогнозов, основанных на бухгалтерских переменных, выше, чем прогнозов от Value Line, построенных на дивидендах (68\% против 29\%).

Вместе с тем Франкел и Ли (Frankel and Lee, 1998) адаптировали модель ЕВО для оценки фундаментальной стоимости собственного капитала фирмы (V) и оценили способность модели объяснять изменения в ценах акций американских компаний. В качестве суррогатного показателя рыночных ожиданий относительно доходов, используемых в модели EBO, выступили консенсус-прогнозы доходов от I/B/E/S. Их исследование показало, что оценка фундаментальной стоимости собственного капитала имеет большую взаимосвязь с ценами акций (P), чем балансовая стоимость (BV). Соответственно, они показали, что показатель V/P имеет большую предсказательную способность относительно доходностей, чем индикатор BV/P. Полученные результаты привели авторов к выводу, что большая часть исследований с применением рыночных мультипликаторов, основанных на бухгалтерской информации, может быть улучшена путем модификации данных индикаторов, через использование показателя экономической прибыли, расчитанного по модели ЕВО.

Ли, Майерс и Сваминатан (Lee, Myers and Swaminathan, 1999) использовали модель EBO для расчета фундаментальной стоимости 30 акций из индекса DJIA. B отличие от других исследователей данной области, они использовали анализ интегрированных и коинтегрированных временных рядов для оценки связи между рыночной ценой и стоимостью. Использование данного инструмента позволило авторам сделать предпосылку о сходимости в долгосрочном периоде рыночной цены и стоимости. Исследователи обнаружили, что показатель V/P имеет большую предсказательную силу в области прогнозирования рыночных доходностей, чем индикаторы BV/P, Earnings/P, Dividends/P. B то же время они сделали вывод, что результат, полученный при использовании показателя $\mathrm{V} / \mathrm{P}$, зависит от качества аналитических прогнозов доходов и ставок дисконтирования.

Однако ряд исследователей не согласны с тем, что оценки стоимости, полученные в рамках методов дисконтирования дивидендов, дисконтирования денежных потоков и модели EBO, идентичны. Подтверждение тому можно найти в работе Френсиса, Олссона и Освальда (Francis, Olsson, Oswald, 2000), где сравниваются надежность оценок фундаментальной стоимости акций, полученных исходя из применения моделей дисконтирования дивидендов, дисконтирования денежных потоков и модели ЕВО. Надежность стоимостных оценок измеряется через призму точности и объясняющей способности. Точность оценивается с помощью формулы $(V-P) / P$, где $V$ - стоимость, рассчитанная с помощью моделей дисконтирования дивидендов, дисконтирования денежных потоков и модели ЕВО. Объясняющая способность в работе измеряется с помощью построения парных регрессий, где зависимой переменной выступает рыночная цена, а независимой - оценка стоимости, полученная в рамках каждой из трех моделей поочередно. Выборка сформирована на основе прогнозов дивидендов, доходов и балансовой стоимости, полученных от Value Line за период с 1989 по 1993 год. В результате авторы пришли к выводу о том, что оценки стоимости акций по модели ЕВО превосходят оценки, полученные в рамках моделей дисконтирования дивидендов и дисконтирования денежных потоков. 
Вместе с тем исследования Дечоу, Хаттона и Слоана (Dechow, Hutton and Sloan, 1999) показали, что модель ЕВО не имеет существенных преимуществ перед другими моделями оценки. Они оценили адекватность модели ЕВО для американских фирм, используя модель информационной динамики Ольсона, рассчитанную по прогнозным и фактическим бухгалтерским данным из I/B/E/S за период с 1976 по 1995 год. Авторы пришли к выводу о том, что рассмотрение связи между текущей информацией и будущими остаточными доходами (информационной динамикой по модели Ольсона) является ошибочным и не дает никаких преимуществ по сравнению с моделью дисконтирования дивидендов и иными традиционными моделями оценки.

Таким образом, проведенные исследования с использованием модели ЕВО показали ее валидность и в некоторых случаях - превосходство над иными моделями оценки. Однако данные работы осуществлялись на основе выборки, составленной из американских компаний. Соответственно «для того, чтобы любая концепция действительно была универсальной, она должна быть проверена в странах, отличных от той, где она была разработана» (Wallace and Gernon, 1991). Франкель и Ли (Frankel and Lee, 1998) оценили способность модели ЕВО предоставлять сопоставимые оценки стоимости компаний на выборке из 20 международных компаний с различными бухгалтерскими системами за период 8 лет, с 1987 по 1994 год. Для оценки будущих доходов в рамках модели ЕВО были использованы прогнозы аналитиков. В качестве инструментария использовался регрессионный анализ, где в качестве зависимой переменной выступала цена акции, а независимыми - балансовая стоимость, доходы и стоимость, полученная в рамках модели ЕВО. Задачей было исследование объясняющей способности данных факторов. Результаты показали, что с позиции точности прогнозы доходов американских фирм, сделанные зарубежными аналитиками, являются сопоставимыми с ожиданиями американских аналитических агентств. Кроме того, исследование выявило, что стратегии хеджирования рисков, основанные на индикаторе $V / P$, приводят к относительно постоянным положительным доходностям. Основываясь на данных результатах, Франкель и Ли пришли к выводу, что фундаментальная стоимость, измеренная с помощью модели ЕВО, не подвержена влиянию различий в системах бухгалтерского учета по странам. Кроме того, данная стоимость больше связана с ценами акций, чем балансовая стоимость и доходы.

В целом данная модель отражает, каким образом рыночная стоимость фирмы соотносится с данными, представленными в бухгалтерской отчетности. Последние, в рамках модели, касаются результатов операционной и финансовой деятельности. Однако каждая из этих двух видов деятельности выявляет различные проблемы измерения результатов в рамках бухгалтерской отчетности. Подобные обстоятельства влияют на анализ рыночной стоимости фирмы как функции компонентов финансовой отчетности. Согласно модели, финансовая деятельность включает в себя операции с активами и обязательствами, для которых существуют относительно идеальные рынки, при этом вводится достаточно жесткое предположение о том, что бухгалтерские измерения относительно данных активов/обязательств сделаны таким образом, что их балансовые и рыночные стоимости совпадают. При этом в модели предполагается, что для операционных активов (дебиторская задолженность, запасы и т.д.) не существует идеальных рынков, где они бы торговались в индивидуальном порядке.

Отчасти это справедливое высказывание, однако Ольсон делает его единственным доводом в пользу различий между рыночной и балансовой стоимостью. Последнее он связывает с различными положениями бухгалтерского учета относительно начислений и их использованием в качестве корректировки операционных доходов для получения денежных потоков. Однако наиболее слабым местом модели является ее ядро, а именно принцип «чистого прироста», когда балансовая стоимость изменяется только за счет полученных прибылей и выплаченных дивидендов, без учета влияния на собственный капитал эффектов от выпуска/выкупа акций и формирования резервов. Тем не менее анализ проведенных исследований показал, что модель EBO имеет преимущества с позиции точности и 
предсказательной способности по сравнению с традиционными моделями оценки, такими как DCF. Хотя последняя на практике имеет большую гибкость по сравнению с EBO, поскольку позволяет осуществлять корректировки каждого компонента денежных потоков (Lee, 1996).

Таким образом, проанализировав модели EVA и EBO, можно предположить, что показатель экономической прибыли, рассчитанный по модели $\mathrm{EBO}$, лучше, чем экономическая добавленная стоимость, объясняет изменение стоимости собственного капитала компаний. Для проверки данной гипотезы необходимо провести эмпирическое исследование, включающее следующие этапы:

- Формализация моделей взаимосвязи индикаторов рыночной капитализации и показателей.

- Описание алгоритма расчета необходимых показателей.

- Сбор базы данных.

- Тестирование моделей и интерпретация результатов.

\section{Модели исследования и формирование базы данных}

Для выявления показателя, который бы отражал изменение стоимости компании, было построено две спецификации модели.

Во-первых, модель взаимосвязи показателей экономической прибыли по моделям EVA и EBO с рыночной капитализацией собственного капитала компании. Также для проверки качества обеих моделей экономической прибыли в качестве фактора был рассмотрен традиционный бухгалтерский показатель чистой прибыли.

$$
P_{t}=a_{1}+a_{2} * X_{t}+\varepsilon
$$

где:

$P_{t}$ - рыночная капитализация собственного капитала компании на конец периода $t$;

$X_{t}$ - показатель стоимости компании: EVA, экономическая прибыль по модели ЕВО или чистая прибыль (ЕАТ) на конец периода $t$;

$a_{1}$ - свободный член;

$a_{2}-$ коэффициент при независимой переменной;

$\varepsilon$ - случайная ошибка модели.

Во-вторых, была построена модель взаимосвязи показателей EVA и экономической прибыли по модели ЕВО с рыночной добавленной стоимостью MVA. Данный показатель определяется как разность между рыночной капитализацией компании и величиной ее собственного капитала на конец периода $t$ (Stewart, 2003). Показатель MVA характеризует способность компании создавать стоимость сверх стоимости вложенных в нее чистых активов, то есть эффективность работы менеджмента и компании в целом с точки зрения акционеров (Stern, 2001).

Соответственно, результаты тестирования данной спецификации модели позволят определить, какой из показателей лучше объясняет превышение рыночной стоимости над балансовой оценкой чистых активов.

$$
M V A_{t}=a_{1}+a_{2} * X_{t}+\varepsilon
$$

где:

$M V A_{t}-$ рыночная добавленная стоимость компании на конец периода $t$.

В рамках следующего этапа исследования представлен алгоритм расчета используемых показателей.

$$
E V A_{t}=N O P A T_{t}^{a d j}-W A C C^{*} I C_{t-1}^{a d j} .
$$

$N O P A T_{t}^{a d j}$ - чистая операционная прибыль за период $t$, скорректированная на величину изменения сомнительных резервов, изменения отложенных налоговых обязательств, изменения расходов на НИОКР и проценты по операционному лизингу. Оценка процентов 
по операционному лизингу произведена по методологии, предложенной Янгом и О’Бирном (Young, O'Byrne, 2000), при предположении, что ставка по операционному лизингу равна ставке по заемному капиталу компании в целом.

$I C_{t-1}^{a d j}$ - инвестированный капитал на конец периода $(t-1)$, скорректированный на неоперационные активы (денежные средства, высоколиквидные ценные бумаги, незавершенное строительство), операционный лизинг, расходы на НИОКР, резервы по сомнительным долгам.

Корректировка инвестированного капитала на операционный лизинг заключается в добавлении приведенной стоимости всех лизинговых платежей, указанных в отчетности, по которым известен точный год платежа, дисконтированных по доналоговой ставке по заемному капиталу (Young, O'Byrne, 2000). Что касается поправки на расходы на НИОКР, то она проводилась путем добавления к инвестированному капиталу величины капитализированных расходов на НИОКР (срок амортизации исследовательского актива составил от 3 до 5 лет) (Young, O'Byrne, 2000). Тем не менее следует отметить, что только 10 компаний из выборки публикует информацию о расходах на исследования и разработки и их величина существенно ниже инвестированного капитала в целом $(10 \%$ для ОАО «Вымпелком» и менее 1\% для всех остальных компаний). Однако, поскольку поправка на расходы на НИОКР существенно влияет на значение чистой операционной прибыли, для согласованности показателей инвестированный капитал также был скорректирован.

$W A C C$ - средневзвешенные затраты на капитал, для расчета которых использованы гибридная модель САРМ для развивающихся рынков при определении затрат на собственный капитал, и модель синтетического кредитного рейтинга для определения затрат на заемный капитал.

$$
E B O_{t}=E A T_{t}^{a d j}-K_{e}^{*} E_{t-1}^{a d j} .
$$

$E A T_{t}^{a d j}$ процентов, очищенных от налога на прибыль.

$E_{t-1}^{a d j}$ - собственный капитал на конец периода $(t-1)$, скорректированный на такие неоперационные активы, как денежные средства и высоколиквидные ценные бумаги.

Еще одним важным аспектом является измерение показателя рыночной капитализации собственного капитала компании. Как правило, в аналитических материалах фондовых рынков капитализация компаний рассчитывается как среднее за квартал. Таким образом, исключается влияние случайных дневных колебаний, присущих фондовому рынку, и капитализация приближается к внутренней, фундаментальной стоимости. Кроме того, встает вопрос о периоде, за который следует брать значение капитализации. С одной стороны, исследуя влияние фундаментальных факторов на конец года, необходимо использовать величину стоимости компании на конец года. С другой стороны, стоимость акций определяется инвесторами на основе отчетности компании.

Бидл, Боуэн и Уоллес при исследовании зависимости рыночной доходности от различных финансовых параметров использовали данные по 12-месячной доходности за период, заканчивающийся через три месяца после окончания финансового года компании, чтобы информация, содержащаяся в годовом отчете фирмы, успела отразиться в ценах фондового рынка (Biddle, 1997).

В своей работе Бухвалов и Волков обосновывают использование рыночных данных по капитализации за второй квартал тем обстоятельством, что инвесторам необходимо время, чтобы более «точно» отреагировать на появление данных новой финансовой отчетности, а также тем, что отчетность публикуется не сразу, а в течение квартала (Бухвалов, Волков, 2005). Причем в их работе используется неконсолидированная финансовая отчетность, которая публикуется раньше консолидированной. В данной работе использована именно консолидированная финансовая отчетность компании, публикация которой происходит в середине II квартала. Таким образом, встает вопрос о выборе между II и III кварталом года. 
При этом следует сказать, что при использовании рыночных данных за III квартал проходит значительный временной интервал между моментом измерения показателей, характеризующих фундаментальные факторы, и моментом измерения капитализации, что означает значительное влияние других факторов. Также, вероятно, различные инвесторы ориентируются на различные формы отчетности, и им требуется различное время для реакции на информацию из финансовой отчетности. Поскольку логически обосновать выбор того или иного периода не представляется возможным, решение данного вопроса может быть осуществлено на основе анализа конкретной выборки.

Для исследования силы взаимосвязи стоимости компании и показателей EVA и экономической прибыли по модели EBO была сделана выборка российских компаний и собраны статистические данные. Поскольку исследование базируется на рыночной стоимости собственного капитала компании, определяемой по данным рынка ценных бумаг, то для корректности результатов исследования временной интервал был ограничен докризисным периодом. Таким образом, собраны статистические данные за 2006-2007 годы, а также некоторые данные за 2005 год, необходимые для расчета экономической добавленной стоимости за 2006 год.

Во-первых, поскольку в качестве зависимой переменной выступает рыночная стоимость собственного капитала компании, то есть капитализация, то в выборку вошли исключительно открытые акционерные общества.

Во-вторых, было решено использовать данные финансовой отчетности компаний по международным стандартам финансовой отчетности (International Financial Reporting Standards, IFRS) и по стандартам бухгалтерского учета, принятым в США (Generally Accepted Accounting Principles, GAAP). Такое решение продиктовано тем, что данные стандарты требуют более подробного раскрытия информации о деятельности компании и более справедливой оценки активов и пассивов компании, чем российские стандарты. Следовательно, благодаря этому в исследовании можно будет более корректно оценить эффективность деятельности и другие характеристики компании. А также можно предположить, что для инвесторов такой формат отчетности более показателен и их оценки стоимости компании зависят от результатов и величин, представленных в отчетности по данным стандартам.

В-третьих, в выборку были включены только нефинансовые компании, поскольку финансовые институты имеют значительные отличия от производственных компаний, следовательно, это позволило повысить однородность выборки.

Используя базу данных SPARK (spark.interfax.ru), была составлена выборка из 98 компаний, являющихся открытыми акционерными обществами, применяющих стандарты бухгалтерской отчетности IFRS и GAAP и функционировавших на конец 2005 года.

В-четвертых, из выбранных компаний были исключены те, по которым отчетность по стандартам IFRS и GAAP отсутствовала хотя бы за один год из рассматриваемого периода в 2005-2007 годы. Также были исключены компании, не допущенные к обращению на торговых площадках Московской межбанковской валютной биржи (ММВБ) и Российской торговой системы, поскольку для них невозможно было рассчитать капитализацию. Рыночная капитализация компаний на РТС рассчитывается и публикуется один раз в квартал. Для акций, торгуемых на ММВБ, она была рассчитана аналогичным образом на основании статистических данных информационного ресурса Investfunds. В результате была составлена выборка из 60 российских нефинансовых компаний, акции которых торгуются на фондовых биржах.

Другие данные, такие как безрисковая ставка, рыночная премия и безрычаговая бета для рынка США, премия за страновой риск для России, соотношение между коэффициентом покрытия процентов и спредом дефолта компании, были взяты с официального сайта Дамодарана.

После формирования базы данных была проверена линейная зависимость рыночной капитализации с фундаментальными показателями. На созданной выборке она ослабевает от 
II квартала к III. Соответственно, можно сделать вывод, что инвесторы реагируют на финансовые результаты деятельности компаний практически сразу после публикации отчетности, а за временной лаг в один квартал изменение внешних и внутренних факторов оказывает значительное воздействие на оценки инвесторов.

Анализ данных проводился с помощью эконометрического пакета EViews. Ниже представлена описательная статистика переменных, задействованных в моделях (табл. 1).

Таблица 1

Описательная статистика данных

\begin{tabular}{|l|r|r|r|r|r|r|}
\hline & EBO & EVA & \multicolumn{1}{|c|}{ P } & BVA & \multicolumn{1}{c|}{ EAT } & \multicolumn{1}{c|}{ MVA } \\
\hline Среднее, млрд руб. & 4,2 & 3,4 & 203,9 & 84,0 & 16,0 & 68,7 \\
\hline Медиана, млрд руб. & 0,5 & $-0,1$ & 70,2 & 28,6 & 3,2 & 14,2 \\
\hline Максимум, млрд руб. & 75,6 & 120,5 & 1967,3 & 1025,9 & 234,8 & 706,7 \\
\hline Минимум, млрд руб. & $-75,1$ & $-45,9$ & 2,7 & 0,9 & $-7,5$ & $-693,7$ \\
\hline Стандартное отклонение, млрд руб. & 19,8 & 19,6 & 336,8 & 160,8 & 37,6 & 188,5 \\
\hline Коэффициент асимметрии, доли & 0,9 & 3,7 & 3,1 & 4,0 & 4,1 & 0,3 \\
\hline Коэффициент эксцесса, доли & 11,3 & 23,4 & 14,5 & 21,9 & 21,8 & 8,6 \\
\hline Коэффициент вариации, доли & 4,7 & 5,7 & 1,7 & 1,9 & 2,3 & 68,7 \\
\hline
\end{tabular}

Как видно из представленной статистики, ни одна из переменных не имеет нормального распределения. Коэффициент асимметрии указывает на то, что правый «хвост» распределения длиннее левого. Это ожидаемый эффект, так как любая выборка компаний ограничена «слева», т.е. компании, эффективность деятельности которых значительно ниже средней, перестают существовать в результате банкротства или поглощения. В то время как компании, существенно более успешные, продолжают деятельность. Коэффициент эксцесса больше трех для всех переменных свидетельствует о том, что большинство компаний в выборке имеют приблизительно одинаковый размер и зарабатывают экономическую прибыль, близкую к средней. Следует отметить, что в среднем экономическая добавленная стоимость и показатель экономической прибыли по модели ЕВО имеют положительные значения. Однако при этом около половины компаний имеют отрицательную экономическую прибыль по обеим моделям, то есть разрушают свою стоимость. Рыночная капитализация, балансовая стоимость активов компании и чистая прибыль имеют распределение, близкое к экспоненциальному, что связано в первую очередь с тем, что на фондовых биржах котируются в основном крупные компании.

\section{Тестирование моделей и анализ результатов}

В ходе тестирования моделей были получены следующие результаты. Во-первых, рыночная капитализация лучше объясняется величиной чистой прибыли, чем показателями стоимости. Как видно из таблицы 2, экономическая добавленная стоимость и остаточная чистая прибыль объясняют менее половины изменения капитализации, в то время как показатель чистой прибыли из бухгалтерской отчетности компании отражает $79 \%$ вариации зависимой переменной. 
Результаты тестирования моделей зависимости капитализации от фактора $\mathrm{X}$

\begin{tabular}{|c|c|c|c|}
\hline Модель & $\begin{array}{l}\text { Фактор } \\
(\mathrm{X})\end{array}$ & $\begin{array}{c}\text { Коэффициент при независимой } \\
\text { переменной }\left(\mathbf{a}_{2}\right)^{1}\end{array}$ & Скорректированный $\mathbf{R}^{2}$ \\
\hline 1 & EVA & $\begin{array}{r}10,22 * * \\
(181) \\
\end{array}$ & 0,344 \\
\hline 2 & EBO & $\begin{array}{r}11,94 * * \\
(1,60)\end{array}$ & 0,482 \\
\hline 3 & EAT & $\begin{array}{r}7,96^{* *} \\
(0,54)\end{array}$ & 0,785 \\
\hline
\end{tabular}

${ }^{1}$ В скобках указана стандартная ошибка, ** - коэффициент значим на уровне $1 \%$, * коэффициент значим на уровне $5 \%$.

Во-вторых, оказалось, что качество взаимосвязи показателя экономической прибыли, рассчитанной по модели $\mathrm{EBO}$, с рыночной добавленной стоимостью значительно выше, чем у моделей зависимости MVA от EVA и от чистой прибыли (табл. 3). Таким образом, показатель модели EBO лучше отражает превышение рыночной оценки собственного капитала над балансовой, то есть эффективность использования капитала собственников компании.

Таблица 3

Результаты тестирования моделей зависимости MVA от фактора X

\begin{tabular}{|c|c|c|c|}
\hline Модель & $\begin{array}{c}\text { Фактор } \\
(\mathrm{X})\end{array}$ & $\begin{array}{c}\text { Коэффициент при независимой } \\
\text { переменной }\left(\mathrm{a}_{2}\right)^{1}\end{array}$ & Скорректированный $\mathrm{R}^{2}$ \\
\hline 1 & EVA & $\begin{array}{r}2,86^{*} \\
(1,20)\end{array}$ & 0,073 \\
\hline 2 & EBO & $\begin{array}{r}6,29 * * \\
(0,94)\end{array}$ & 0,424 \\
\hline 3 & EAT & $\begin{array}{r}1,87 * * \\
(0,61)\end{array}$ & 0,124 \\
\hline
\end{tabular}

${ }^{1}$ В скобках указана стандартная ошибка, ** - коэффициент значим на уровне $1 \%$, * коэффициент значим на уровне $5 \%$.

В результате данного исследования, проведенного на выборке российских нефинансовых компаний различных отраслей, было выявлено, что по сравнению с экономической добавленной стоимостью и чистой прибылью показатель экономической прибыли, рассчитанный по модели ЕВО, является более предпочтительным для оценки инвестиционной привлекательности компании.

Однако в объяснении величины капитализации собственного капитала компании показатель ЕВО уступает чистой прибыли. Данные результаты могут свидетельствовать о том, что из-за низкой информационной эффективности российского фондового рынка, ожидания и, следовательно, требования к доходности у инвесторов неоднородны. Кроме того, константа $\left(a_{1}\right)$ во всех вариантах модели составляет около половины от среднего значения независимой переменной, что свидетельствует о наличии и значительном влиянии других факторов, помимо представленных в исследовании, которые определяют инвестиционную привлекательность собственного капитала компании. Помимо этого может быть проанализирована выборка из большего количества наблюдений или включающая более однородные данные. Подобные обстоятельства формируют почву для будущих исследований в данном направлении. 


\section{Список литературы}

1. Ивашковская И.В., Слободина,М.В. Эмпирический анализ экономической прибыли телекоммуникационных компаний в странах с развивающимися рынками капитала // Корпоративные финансы. 2009. № 2. C. 57-69. URL: http://ecsocman.hse.ru/hsedata/2010/12/31/1208184353/Vypusk10_ivashkovskaya_slobodin a_57_69.pdf.

2. Романов В.С., Кукина Е.Б. Исследование взаимосвязи показателя EVA и стоимости компании на российском рынке капитала // Корпоративные финансы. 2008. № 4. С. $38-57$.

URL: http://ecsocman.hse.ru/hsedata/2010/12/31/1208181386/Vypusk8_38_57_romanov_kukina. pdf.

3. Bernanrd, V. (1995), The Feltham-Ohlson framework: Implications for empiricists, Contemporary Accounting Research, 11(Spring) (1995) 733-747.

4. Biddle, G.C., Bowen, R.M., Wallace, J.S. (1999), Evidence on EVA, Journal of Applied Corporate Finance, 12 (1999) 69-79.

5. Chen, S., Dodd, J. (2002), Market Efficiency, CAPM, and Value-relevance of Earnings and EVA: A Reply to the Comment by Professor Paulo, Journal of Managerial Issues, 14(4) (2002) 507-512.

6. Damodaran, A.: www.damodaran.com.

7. Dechow, P.M., Hutton, A.P., and Sloan, R.G. (1999), An empirical assessment of the residual income valuation model, Journal of Accounting and Economics, 26(January) (1999) $1-34$.

8. Feltham, G.A., and Ohlson, J.A. (1995), Valuation and clean surplus accounting for operating and financial activities, Contemporary Accounting Research, 11(Spring) (1995) 689-731.

9. Fernandez, P. (2001), EVA and Cash Value Added Do Not Measure Shareholder Value Creation, May 23 (2001) 17.

10. Francis, J., Olsson, P., and Oswald, D.R. (2000), Comparing the accuracy and explainability of dividend, free cash flow and abnormal earnings equity value estimates, Journal of Accounting Research, 38(Spring) (2000) 45-70.

11. Frankel, R., and Lee, M.C. (1998), Accounting valuation, market expectation, and crosssectional stock returns, Journal of Accounting and Economics, 25(June) (1998) 283-319.

12. Investfunds: http://investfunds.ru.

13. Ismail, A. (2006), Is economic value added more associated with stock return than accounting earnings? The UK evidence, International Journal of Managerial Finance, 4(2) (2006) 343-353.

14. Kim, W.G. (2006), Eva and traditional accounting measures: which metric is a better predictor of market value of hospitality companies?, Journal of Hospitality \&amp; Tourism Research, (2006) 34-49.

15. Lee, C. (1996), Measuring wealth, CA Magazine, 129(April) (1996) 32-37.

16. Lee, C., Myers, J. and Swaminathan, B. (1999), What is the intrinsic value of the Dow?, Journal of Finance, 54(October) (1999) 1693-1741.

17. Maditinos, D., Sevi, Z., Theriou, N. (2009), Economic Value Added (EVA). Is it Really the Best Performance Measure? A Review of the Theoretical and Empirical Literature. The case of Athens Stock Exchange (ASE), Journal of Modelling in Management, 3(4) (2009) 182 201.

18. Marshal,1 A. (1890), Principles of Economics, New York: MacMillan \& Co., 1 (1890) 142.

19. O'Byrne, S. (1996), EVA and Market Value, Journal of Applied Corporate Finance, 9 (1996) $116-125$.

20. Ohlson, J.A. (1995), Earnings, book values, and dividends in security valuation, 
Contemporary Accounting Research, 11(Spring) (1995) 661-687.

21. Pohlman, R.A., Gardiner, G.S. (2000), Value Driven Management: How to Create and Maximize Value over Time for Organizational Success, New York: Pohlman, Inc. P. 240.

22. Stern, J.M., Shiely, J.S., with Irwin Ross. (2001), The EVA challenge: implementing value added change in an organization. New York: Wiley\&Sons, Inc. P. 250.

23. Stewart, T. (2003), The Wealth of Knowledge: Intellectual Capital and the Twenty-First Century Organization. NY: Doubleday Dell Publishing Group. P. 416

24. Tsuji, C. (2006), Does EVA beat earnings and cash flow in Japan?, Applied Financial Economics, 16(16) (2006) 1199-1216.

25. Visaltanachoti, N., Robin, L., Yi, Y. (2008), Economic Value Added (EVA) and sector returns, AAMJAF, 2(4) (2008) 21-41.

26. Wallace, R., and Gernon, H. (1999), Frameworks for international comparative financial accounting, Journal of Accounting Literature, 10 (1999) 209-264.

27. Worthington, A.C., West, T. (2004), Australian Evidence Concerning the Information Content of Economic Value-Added, Australian Journal of Management, 2(29) (2004) 201224.

28. Young, S. D., O'Byrne, S.F.: EVA and Value-Based Management: A Practical Guide to Implementation, McGraw-Hill Professional Book Group. P. 493. 